\title{
HYPNOPARENTING; SEBUAH METODE MENJINAKKAN ALLIGATOR'S BRAINS PADA ANAK USIA DINI
}

\author{
Risa Alfiyah Ulfa \\ Instutut Agama Islam Sunan Giri (INSURI) Ponorogo \\ risaalfiyahulfa@gmail.com
}

\begin{abstract}
; every child must bring up the alligator's brain as a form of impinging psychological discomfort. Alligator's brain is a negative action taken by a child. The child's attitude is a reflection of what is done by the people closest to him, including the family which is the smallest community in children's education. Families play an important role in the realization of children who have good characteristics. Children who make negative actions are most likely because the closest environment is doing negative things, and vice versa. It takes a method that is able to minimize and even eliminate alligator's brain that is often raised by children when their psychological condition is uncomfortable. Hypnoparenting is a method that is able to tame alligator's brain. Hypnoparenting is an attempt by parents to bring children to the subconscious with the aim of influencing the child's mindset with which children can do good or bad. Hypnoparenting brings children from beta brain waves through alpha to tetha. When it reaches the wave of tetha, the child is able to accept positive suggestions from parents as an effort to tame the alligator's brain in children. Hypnoparenting provides maximum results if done continuously every day.
\end{abstract}

Keywords; hypnoparenting, alligator's brain.

\section{PENDAHULUAN}

Proses lahirnya anak ke dunia merupakan saat yang paling ditunggu-tunggu oleh orang tua. Memiliki anak merupakan suatu hal yang menyenangkan dan membahagiakan. Orang tua mulai mengembangkan kegiatannya menjadi seorang ayah dan ibu dengan kecakapan mendidik serta mengasuh anak dengan baik dan benar. Kecakapan mereka dalam mendidik dan mengasuh anak dapat dilihat dari bagaimana sang anak bersikap dan bertutur kata.

Orang tua sering dihadapkan dengan tingkah laku anak yang membuat mereka kewalahan dalam mengatasi dan menghentikan perbuatan negatif anak, seperti halnya munculnya perilaku tantrum oleh seorang anak usia dini yang salah satunya pernah penulis ketahui di desa Sukosari kecamatan Babadan kabupaten Ponorogo. Perilaku yang dimunculkan oleh anak adalah menangis sambil menjerit serta berguling-guling sembari berteriak di tempat umum. Sang anak merasa tidak nyaman karena sesuatu yang menjadi keinginannya tidak terpenuhi saat itu. Melihat kejadian tersebut, ibu secara spontan memarahi anak dan mencubit lengan anak dengan tujuan agar anak diam. Hasilnya adalah anak semakin menjerit kesakitan dan berteriak kencang.

Penyebab munculnya perilaku negatif yang dilakukan anak di antaranya adalah; Pertama, pola asuh. Keluarga merupakan komunitas terkecil dalam lingkungan pendidikan yang 
memainkan peran penting guna mengasuh dan mendididik anak. Keluarga adalah cerminan ucapan dan perilaku anak. Pengasuhan yang salah akan memberikan pengaruh terhadap tumbuh kembang anak. Kedua, faktor institusi pendidikan formal. Hal ini akan memengaruhi fungsi emosi dan psikososial anak. Ketiga, lingkungan sekitar seperti teman sebaya, gadget, dan lain sebagainya. Dari lingkungan tersebut anak belajar bersikap dan berucap sesuai dengan apa yang dilihat baik yang bersifat positif maupun negatif (Riggins-Caspers, dkk, 2003)

Menurut Dewi Yogo dalam bukunya yang berjudul Hypno Parenting, setiap anak selalu memunculkan sikap negatif yang dinamakan alligator's brain sebagai salah satu cara meluapkan emosi dan ketidaknyamanan saat menghadapi suatu hal. Alligator's brain merupakan bentukan makna dari primitive instinc. Primitive berarti keadaan manusia sebelum peradaban. Saat itu yang berlaku hanya hukum rimba, yang kuat akan menang dan bertahan. Akibatnya banyak sekali muncul perilaku negatif. Instinc merupakan sifat mutlak yang hanya dimiliki hewan sehingga primitive instinc ini juga bisa diistilahkan sebagai alligator's brain. Dianalogikan sebagai alligator's brain karena alligator's brain adalah sejenis buaya yang digambarkan sebagai derivasi hewan purba paling jahat yang tersisa di muka bumi ini. Lebih lanjut, Dewi Yogo Pratomo menjelaskan bahwa alligator's brain pada anak dapat dijinakkan dengan metode Hypnoparenting (Dewi, 2012).

Senada dengan pedapatnya Dewi Yogo, salah satu dosen fakultas Psikologi Universitas Negeri Yogyakarta (UNY), Rita Eka berpendapat bahwa metode hypnoparenting merupkan metode yang cocok untuk menjinakkan alligator's brain yang sesuai dengan karakteristik anak. Pendapat ini beranjak dari keyakinan bahwa otak manusia terdiri atas otak sadar dan otak bawah sadar. Akumulai otak sadar anak adalah 5\% yang penuh dengan sikap melawan (alligator's brain) sementara otak bawah sadar anak 95\% yang mudah dikendalikan orang lain. Otak bawah sadar adalah otak perasaan, emosi dan merupakan long term memory yang akan diingat anak hingga dewasa. Artinya, perintah dan kata-kata orang tua 95\% masuk ke pikiran anak tanpa disaring lagi, sehingga alligator's brain yang dimunculkan anak mampu dijinakkan dengan hypnoparenting (Rita, 2008).

Di sini dapat digaris bawahi bahwa peran orang tua sangat penting dalam mendidik anak agar anak mampu mengontrol emosinya sehingga tidak terjerumus oleh hal-hal negatif. Dalam mendidik anak pun harus dengan cara yang tepat. Walaupun orangtua memiliki kesibukan, orangtua harus tetap mendidik dan mengasuh anak dengan penuh kasih sayang. Sebagaimana beberapa pendapat yang telah dijelaskan di atas. Dengan demikian, penelitian ini dianggap 
penting. Peneliti hendak membahas metode Hypnoparenting yang digunakan sebagai metode ampuh untuk menjinakkan alligator's brain pada anak.

\section{METODE}

Pendekatan penelitan ini adalah kualitatif yang bersifat deskriptif-interpretatif. Jenis penelitian adalah library research. Data yang diperoleh adalah wacana deskriptif mengenai gejala dan fenomena sosial yang menyangkut alligator's brain pada anak usia dini. Sebagai penelitian library research, teknik pengumpulan data adalah dokumentasi. Peneliti terus berupaya menggali data terutama yang menyangkut alligator's brain dengan dokumentasi. Kemudian, analisis data menggunakan grounded research, yakni awalnya peneliti menggeneralisasi data dan permasalahan alligator's brain dengan teori Hypnoparenting. Dari hasil generalisasi kemudian disajikan sintesis-tesis.

\section{HASIL DAN PEMBAHASAN}

\section{Redefinisi Hypnoparenting dalam Lingkup Psikologi Anak}

\section{Terminologi Hipnosis}

Kata hipnosis pertama kali diperkenalkan oleh James Braid, seorang dokter ternama di Inggris yang hidup antara tahun 1795-1860. Sebelum masa James Braid, hipnosis dikenal dengan nama "mesmerism" atau "magnetism". Di Indonesia, hipnosis disebut dengan hipnotis, hipnotisme atau hipnosis. Hipnosis berasal dari kata "hypnos" yang artinya dewa tidur orang Yunani. Akan tetapi makna tidur adalah ketika seseorang berada dalam alam tidak sadar dan tidak mampu mendengar suara-suara sugesti. Berbeda dengan hipnosis yang masih bisa mendengar dan merespon suara yang diterimanya meskipun dalam keadaan istirahat (Indra, 2012).

Metode hipnosis telah digunakan dan diterapkan oleh banyak kalangan mulai dari paramedik untuk terapi penyakit fisik, penyakit jiwa, kemudian juga dalam bidang hukum dan kriminalitas. Tak jarang juga metode ini digunakan dalam dunia entertainment dan bidang manajemen. Bahkan saat ini dunia pendidikan pun juga antusias dalam penelitian tentang metode ini hingga penerapan metode hipnosis.

Hal demikian sangat tidak mengherankan karena hipnosis telah berkembang sejak 2.600 tahun sebelum masehi yang dalam praktiknya dikenal dengan istilah "hypnoterapi". Hipnosis merupakan suatu istilah yang asing didengar oleh masyarakat. Banyaknya tindak kejahatan yang memiliki kemiripan dalam penggunaannya memunculkan image negatif dari masyarakat. Image negatif tersebut tampak karena adanya persepsi yang salah akan kegunaan dari hipnosis seperti 
gendam yang dilakukan untuk mencopet dan lain lain. Terlebih adanya acara di televisi yang menggunakan teknik yang hampir sama dengan hipnosis menjadikan masyarakat banyak beropini salah tentang hypnoterapi (Dewi, 2012).

Senada dengan dengan pengertian tersebut, terdapat definisi lain mengenai hipnosis yaitu seni komunikasi untuk memengaruhi seseorang sehingga mengubah tingkat kesadarannya dengan cara menurunkan gelombang otak dari betha ke alpha atau tetha (Muhammad, 2012). Keadaan seseorang menjadi terhipnosis apabila gelombang pikiran berada dalam level alpha dan tetha. Pengalaman dan pengetahuan yang diterima langsung bersarang di alam bawah sadar yang mengakibatkan pikiran nyaman, tenang, rileks, dan santai (Muhammad, 2012).

Dari beberapa istilah di atas dapat peneliti tarik kesimpulan bahwa hipnosis adalah suatu keadaan dimana seseorang diberikan sugesti dalam pikiran alam bawah sadar sehingga memengaruhi pola pikir untuk berbuat baik atau buruk.

\section{Macam-macam Hipnosis}

Berdasarkan masanya, ilmu hipnosis terbagi menjadi dua, yaitu hipnosis klasik dan hipnosis modern. Hipnosis klasik merupakan imu hipnosis dengan bantuan jin, tenaga dalam, hal-hal yang berhubungan dengan alam ghaib dan seringkali digunakan untuk hal-hal negatif seperti gendam. Hipnosis modern adalah jenis hipnosis yang dilakukan secara verbal maupun non verbal dengan tujuan memberikan sugesti kepada seseorang secara alami tanpa menggunakan ritual-ritual tertentu (Septian, 2012). Hipnosis modern terbagi menjadi dua jenis, yaitu stage hypnosis dan hypnotherapy. Stage Hypnosis adalah ilmu hipnosis yang digunakan di atas panggung atau dengan tujuan sebagai entertain/hiburan. Seperti yang sering kita tonton di televisi, aksi Romy Rafael, Dedy Cobuzier, Ferdian, dan master lainnya. Adapun hypnotherapy adalah jenis hipnosis yang dilakukan secara verbal maupun non verbal dengan tujuan agar seseorang menjadi lebih baik dengan membawa pasien pada gelombang theta sehingga mudah untuk disugesti. Hypnotherapy digunakan sebagai usaha yang bisa digunakan untuk penyembuhan penyakit pikiran seperti trauma, depresi, paranoid, fobia, dendam, kecanduan, kebiasaan buruk, malas, tidak percaya diri, pemalu, latah, dan lain sebagainya.

Lebih lanjut berdasarkan manfaatnya, hipnosis dibagi menjadi lima, di antaranya; Hypnotherapy/Clinical Hypnosis, Medical and Dental Hypnosis, Comedy Hypnosis, Forensic Hypnosis, dan Metaphysical Hypnosis.

1. Hypnotherapy atau Clinical Hypnosis, adalah aplikasi hipnosis guna menyembuhkan gangguan mental dan meringankan gangguan fisik. Jenis hipnosis ini mampu menghilangkan penyebab 
terjadinya suatu penyakit sehingga penyakit yang diderita pasien dapat sembuh permanen dalam waktu singkat.

2. Medical and Dental Hypnosis, yaitu penggunaan hipnosis untuk dunia medis terutama oleh dokter ahli bedah dan dokter gigi guna menciptakan efek anesthesia tanpa menggunakan obat bius. Teknik ini telah dilakukan pertama kali oleh Elliotson, seorang doketr bedah yang menggunakan teknik ini tanpa rasa sakit sebelum ditemukannya obat bius.

3. Comedy Hypnosis adalah hipnosis yang digunakan untuk hiburan semata. Hipnosis ini dapat dipelajari oeh siapapun yang hanya dengan hitungan jam. Sebagai contoh komedian yang ada dipanggung mampu membuat seluruh orang yang melihatnya tertawa. Seluruh penonton terbius dengan aksi sang komedian tanpa harus meminta izin untuk dihipnosis. Akan tetapi jika para penoton menolak dihipnosis atau dapat dikatakan tidak menemukan aksi lucu dari komedian yang berada di atas panggung tersebut, maka tidak akan muncul pengaruh hipnosis kepada penonton.

4. Forensic Hypnosis, dapat diartikan dengan metode hipnosis, yakni alat bantu untuk melakukan investigasi dalam pikiran bawah sadar seseorang. Pada umunya metode ini digunakan dalam mengatasi permasalahan kriminal yaitu membantu saksi dalam mengingat kembali kejadian yang telah dilihat dan dialaminya dalam suatu kasus. Metode jenis ini digunakan ketika seseorang tidak mau mengingat atau tidak mau mengatakan kejadian sebenarnya dari suatu kejahatan yang terjadi.

5. Metaphysical Hypnosis, adalah meode hipnosis yang digunakan untuk meneliti berbagai fenomena metafisik yang bersifat eksperimental seperti meditasi, komunikasi, mengakses kekuatan super conscious mind dan lainnya yang berhubungan dengan metafisika (Indra, 2012).

\section{Parenting}

Secara bahasa "parenting" berasal dari bahasa Inggris "parent" yang berarti "orangtua" (John, 2005). Dalam kamus Oxford dijelaskan bahwa parenting adalah "the process of caring for your child or children" (Hornby, 2010), sedangkan menurut Brooks, parenting merupakan serangkaian interaksi antara orangtua dan anak yang terus berlanjut, dimana proses tersebut mempunyai perubahan kedua belah pihak (Brooks, 1991).

Pendapat lain mengungkapkan, parenting adalah segala sesuatu yang berurusan dengan tugas-tugas orang tua dalam mendidik dan membesarkan anak (Arismantoro, 2018). Adapun menurut Baumrind dalam Lemonda, parenting adalah bagaimana orangtua memberikan kehangatan, mengontrol anak-anaknya untuk melaksanakan tugas perkembangannya menuju 
proses dewasa (Afra, 2017), jadi dapat disimpulkan bahwa parenting adalah pola asuh orang tua untuk memengaruhi pertumbuhan dan perkembangan anak.

\section{Positive parenting}

Pengasuhan dalam positive parenting memiliki beberapa prinsip kunci, yaitu; a) pemenuhan nutrisi anak, nutrisi dapat berpengaruh besar pada perkembangan, konsentrasi, dan kemampuan mental lainnya; b) Kehidupan yang seimbang, dimana anak memiliki kesempatan bermain, belajar, mengeksplorasi lingkungannya dan memiliki waktu yang berkualitas bersama kedua orangtuanya, mengajarkan kehidupan yang seimbang dapat membantu anak memiliki regulasi diri yang baik dan membantu memelihara kedisiplinan dalam kehidupannya; c) Mengembangkan rasa aman dan keamanan dalam keseharian, dilakukan untuk melindungi anak dari dampak lingkungan yang negatif, situasi yang belum waktunya dipahami, dan menciptakan lingkungan yang positif dan aman; d) Memelihara komunikasi yang terbuka kepada anak, teman-temannya, pihak sekolah, dan lingkungan sekitar anak; e) Menjadi orangtua yang aktif, sehingga anak-anak merasa didengarkan, memiliki ikatan yang kuat, dan memahami potensi keterbatasannya. Kesemuanya haruslah diawali dari sikap dan karakter orangtua yang positif baik terhadap kehidupan, dunia, dan keluarga (Darosy, 2010).

\section{Hypnoparenting}

Hypnoparenting merupakan salah satu aplikasi hipnosis untuk tujuan merawat dan mendidik anak (parenting). Daluti dalam Ani menjelaskan bahwa aplikasi hipnosis untuk parenting ini dilakukan tanpa harus membuat seorang anak tertidur, namun dilakukan dengan menyugesti anak dengan kalimat-kalimat yang mampu membuat anak percaya diri dan dengan kata-kata yang halus dan bernilai posistif (Daluti, 2012).

Sementara itu dikutip oleh Arismantoro, bahwa menurut Eva Imania Eliasa (Dosen Fakultas Ilmu Pendidikan UNY), hypnoparenting adalah suatu usaha yang dilakukan oleh orangtua dan pendidik dengan mempetakan dan membuat sistemasi atas segala hal yang berhubungan dengan tugas sebagai orang tua ditinjau dari sudut pandang cara kerja pikiran dan pengaruh agar anak dapat mandiri serta siap mengahadapi masa depannya (Arismantoro, 2018). Hypnoparenting juga dapat diartikan sebagai pembinaan anak dengan memerhatikan pengaruh hipnosis untuk menanamkan rekaman/sugesti positif pada pikiran bawah sadar anak (Bianda, 2010).

Lebih lanjut Dewi (2012) memberikan contoh penerapan hypnoparenting yang ada dalam kehidupan sehari-hari, seperti halnya anak dari suku Padang yang menyukai makanan pedas, sedangkan anak-anak di dataran Cina yang menyukai warna merah. Ini terjadi karena semua 
makanan yang disajikan di Padang memiliki cita rasa pedas. Begitu juga di Cina, warna merah merupakan warna magis yang dipercaya memberikan energi kehidupan. Oleh karena itu, orangtua di sana selalu dominan menggunakan warna merah untuk kesehariannya seperti penggunaan simbol, baju, makanan, ornamen, dan hio. Pengulangan yang tidak langsung ini merupakan hynoparenting yang alami (Dewi, 2012). Hypnoparenting menggunakan prinsip kerja hipnosis dengan pengetahuan tentang bagaimana mendidik dan menjadi orangtua yang mampu memahami perkembangan anak untuk menuju kehidupan yang baik, sukses, dan bahagia (Agus, 2012).

Jadi dapat peneliti simpulkan bahwa hypnopareting dalam penulisan ini adalah usaha yang dilakukan orang tua dengan membawa anak ke alam bawah sadar dengan tujuan untuk memengaruhi pola pikir anak yang dengannya anak dapat berbuat baik ataupun buruk.

\section{Alligator's Brain}

Dalam epistemologi Sosiologi dan Antropologi, dikatakan bahwa setiap manusia melakukan sesuatu karena adanya dorongan yang dinamakan primitive instinc. Hal inilah yang menjelaskan alasan manusia melakukan hal-hal negatif, buruk, destruktif, bahkan kontraproduktif. Primitive berarti keadaan manusia sebeum peradaban, sedangkan instinc adalah sifat mutlak yang hanya dimiliki hewan, sehingga primitive instinc bisa diistilahkan dengan alligaor's brain (Dewi, 2012). Alligator's brain yang terdapat pada anak usia dini adalah sifat-sifat negatif yang dimunculkan anak seperti membatah, malas, berbohong, mencuri, menjahili adik, memukul, dan hiperaktif.

Keberhasilan hypnoparenting dalam menjinakkan alligator's brain pada anak adalah dengan kasih sayang, empati, dan kelembutan hati dari orang tua. Secara fisiologis, saat orangtua menata mata anak dengan tatapan yang sayu, lembut, dan suara yang merdu, maka sebenarnya orangtua telah berhasil mengantar anak masuk dalam gelombang alpha dan tetha. Ini merupakan golden momentum yang tepat sekali untuk mejinakkan alligator's brain yang dimiliki anak. Metode hypnoparenting lebih mudah dan efektif jika dibandingkan ketika orang tua memberi tahu anak dengan mengguakan kekerasan seperti memukul, menghardik, atau bahkan menyumpahinya. Orang tua yang sering memukul anak pada dasarnya tidak menjadikan mereka jera akan tetapi bisa menjadikan mereka semakin menambah perbuatan negatif, karena yang dihukum bukanlah diri anak melainkan organ fisiknya.

Secara empiris, diketahui bahwa 97\% orangtua yang berkata kasar dan memukul berasal dari keluarga yang menerapkan kekerasan dalam rumah tangga (KDRT), entah ia merasakan sendiri ataupun melihat kekerasan di masa kecilnya. Jadi, sebelum orang tua menjinakkan 
alligator's brain anak, maka orang tua harus memastikan apakah sudah mampu menjinakkan alligator's brain pada dirinya sendiri (Dewi, 2012).

Jadi, pada dasarnya segala hal negatif yang ditunjukan oleh anak itu tidak berdiri sendiri, karena anak merupakan cermin orang tuanya. Anak akan meniru setiap apa yang dilakukan ataupun diucapkan oleh orang tuanya baik itu positi atau negatif (mirroring). Jika menginginkan seorang anak yang sopan dan santun, maka orang tua harus bertutur dan berperilaku sopan santun terlebih dahulu.

\section{Cara Kerja Hypnoparenting dalam Menjinakkan Alligator's Brain}

Sebelum berbicara panjang tentang metode Hypnoparenting, Septian El-Syakir memulai dengan pembahasan mengenai gelombang otak. Cara untuk mengetahui atau mengukur gelombang otak anak ialah dengan menggunakan sebuah alat yang bernama EEG (electroenchephalography). Hasil pengukuran tersebut dapat diketahui tingkat kesadaran otak dengan melihat gelombang otak yang tampil pada monitor. Gelombang otak terdiri dari empat frekuensi, di antaranya beta, alpha, theta, dan delta (Septian, 2012).

Beta (kognitif, analitis, logika, konsentrasi, prasangka, aktif, cemas, waswas, khawatir, stres, dan panik). Pada kondisi ini pikiran dalam keadaan sadar. Dalam satu kegiatan bisa berpikir tiga pikiran atau lebih, misalnya dalam satu kegiatan belajar, anak memikirkan tiga pikiran, mendengarkan penjelasan guru, memikirkan game di warnet, dan memikirkan PR yang belum dikerjakan. Jadi, pada frekuensi ini pikiran sedang sangat crowded, sehingga tidak tepat memberikan sugesti atau nasehat pada frekuensi ini atau critical areanya sangat aktif.

Alpha (relaksasi, nyaman, tenang, santai, puas, segar, dan bahagia). Pada kondisi ini keadaannya sudah rileks. Kondisi rileks ini sudah bisa menerima sugesti atau nasehat orangtua dengan baik karena critical areanya sudah mulai menipis. Seperti ketika kita sedang sangat lelah setelah pulang kerja, kemudian duduk di sofa untuk beristirahat, maka frekuensi otak akan menurun dari beta ke alpha. Dalam satu kegiatan seseorang bisa sekaligus memikirkan dua pikiran.

Theta dimaknai sebagai khusyu', deep rilexation, visualisasi, pikiran bawah sadar, ikhlas, dan imajinatif. Pada kondisi ini sudah dalam keadaan sangat rileks dan berada di pikiran bawah sadar, sehingga anak sangat mudah menyerap sugesti positif. Hal ini terjadi saat seseorang mengalami tidur ringan atau dalam kedaan mengantuk. Pada saat ini hanya memikirkan satu pikiran.

Delta dimaknai sebagai tidur lelap, tidak ada pikiran dan perasaan yang aktif. Pada frekuensi ini orang tidur lelap, sehingga sugesti apa pun tidak akan didengarkan dan diterima 
(Septian, 2012). Pada tahap ini biasanya orang kehilangan karena sebab tidur sehingga segala hal terjadi di luar dunianya tidak akan direspon.

Adapun tahapan hypnoparenting yang ideal untuk dilakukan orangtua atau pendidik anak usia dini ada enam adalah;

1. Tahapan pre-talk. Merupakan tahapan awal untuk menggali masalah secara detail terkait dengan pertanyaan mengapa, kapan, bagaimana, dimana, siapa, dan sebagainya. Tahapan ini membutuhkan waktu yang cukup lama karena orangtua atau pendidik harus menggali informasi dari lingkungan tempat anak beraktifitas.

2. Tahapan pre-induction. Merupakan tahapan ketika anak berada dalam posisi nyaman. Anak dapat disandarkan di ruangan yang nyaman kemudin dielus punggung dan kepalanya. Begitu mata dan tubuh tidak lagi digerakan oleh anak.

3. Tahapan induction. Merupakan tahapan ketika anak mulai masuk ke dalam gelombang alpha. Kondisi ini peneliti contohkan dengan kondisi ketika anak baru tertidur. Bola matanya masih bergerak dan anak dipastikan belum sampai tertidur lelap. Posisi ini sangat efektif untuk memasukan sugesti positif kepada anak.

4. Tahapan sugesti. Tahapan dimana anak sudah masuk ke dalam gelombang tetha dan merupakan waktu yang tepat untuk memasukkan sugesti golden moment. Melakukan sugesti harus menghindari kata "jangan" atau "tidak". Misalnya, saat anak sering mengompol dan orang tua memberikan sugesti dengan kata "nak, jangan ngompol!", namun yang terjadi adalah anak justru sering ngompol. Otak anak dalam bawah sadar tidak mampu menerjemahkan kata “jangan” dan "tidak” saat sugesti berlangsung, sehingga sugesti yang dimasukan menjadi sia-sia yang berakibat fatal terhadap perkembangan anak.

5. Tahapan post-hypnotic suggestions. Merupakan tahapan dimana sugesti dimasukkan dan diharapkan dapat menetap (Dewi, 2012).

\section{KESIMPULAN}

Hypnoparenting merupakan usaha yang dilakukan orang tua dengan membawa anak ke alam bawah sadar dengan tujuan untuk memengaruhi pola pikir agar dapat berbuat baik ataupun buruk. Hypnoparenting membawa anak dari gelombang otak beta melalui alpha menuju tetha. Ketika sudah sampai gelombang tetha, anak akan mampu menerima sugesti-sugesti positif dari orang tua sebagai usaha menjinakkan alligator's brain. Alligator's brain merupakan tindakan negatif yang dimunculkan anak ketika kondisi psikologisnya sedang tidak baik. Metode 
Hypnoparenting memainkan peran penting guna membantu orang tua untuk menjinakkan alligator's brain yang dimuncukan anak sedari dini.

\section{ACKNOWLEDGEMENT}

Terimakasih penelti haturkan kepada segenap civitas akademika INSURI Ponorogo terutama Ketua Prodi dan dosen pengampu di Program Studi Pendidikan Islam Anak Usia Dini. Karena dengan bantuannya, peneliti mampu merampungkan penelitian ini dengan baik. Kajian dan diskusi yang telah diberikan sangat memberi arti kepada peneliti guna mengembangkan komplesitas kepenulisan karya ilmiah. Penelitian ini merupakan penelitian individu yang peneliti tulis tanpa mendapat biaya dari luar. Penelitian ini dilakukan guna memenuhi kewajiban salah satu tridarma perguruan tinggi yaitu meneliti.

\section{BIBLIOGRAFI}

Atkinson, Rita, dkk. (2008). Pengantar Psikologi Edisi Kedelapan Jilid 2. Jakarta: Erlangga.

Arismantoro. (2018). Tinjauan Berbagai Aspek Karakter Building;: Bagaimana Mendidik Anak Berkarakter. Tiara Wacana.

Aufia, Afra. (2017). Metode Islamic raenting padda Pengasuh Pondok Pesantren "X". Skripsi. Fakultas Psikologi Universitas Muhammadiyah Purwokerto.

Brooks B, Jane. (2001). Parenting, 3rd edition, Londond. Mayfield Publishing Company.

Delimanugari, Daluti. (2012). Pendidikan Karakter Anak dalam Pendidikan Islam dengan Menggunakan Hypnooparenting Yogyakarta. UIN SUKA Press.

El-Syakir, Septian. (2014). Islamic Hypno Parenting Mendidik Anak Masa Kini Ala Rasulullah. Kawan Pustaka Press.

Hornby, A. (1995). Oxford Advanced Learner's Dictionary of Current English. Oxford University Press.

Hysociamina, Darosi. (2011). "Peran Keluarga dalam Mmembangun Karakter Anak". Jurnal Psikologi UNDIP Vol. 10 No. 2, Oktober 2011.

Majid, Indra. (2012). The Mind Programming Expert, Ebook: Pemahaman Dasar Hypnosis :: Oleh: Indra Majid :: Situs: www.indramajid.com.

Nadia, Bianda. (2010). Hipnotis Metode Terapi Anak dengan Hipnoterapy. Gudang Ilmu.

Nur, Muhammad. (2012). Spiritual Hypno-Parenting. Genius Publisher.

Pratomo, Dewi, (2012). Hypnoparenting Sugesti Positif agar Anak Sehat, Cerdas, Bahagia, dan Berprestasi. Mizan. 
Puspitarini, H. (2015) Hypnoparenting Islami: Mendidik Anak Berbasis Qur'ani. Caesar Media Pustaka.

Riggins-Caspers. (2003). "Biology-Environment Interaction and Evocative Biology-Environment Corelation: Contribution of Harsh Dicipline and Parental Psychopathology to problem Adolescent Behaviors", Jurnal Bhaviors Gentics, Vol. 33 No. 3, May 2003.

Sutiyono, Agus. (2012). Dahsyatnya Hypnoparenting. Penebar Plus. 